\begin{tabular}{|c|c|}
\hline Title & Recovery of rocky intertidal zonation: two years after the 2011 Great East Japan Earthquake \\
\hline Author(s) & Noda, Takashi; Iwasaki, A iko; Fukaya, Keiichi \\
\hline Citation & $\begin{array}{l}\text { Journal of the Marine Biological A ssociation of the United Kingdom, 96(8), 1549-1555 } \\
\text { https://doi.org/10.1017/S002531541500212X }\end{array}$ \\
\hline Issue Date & $2016-12$ \\
\hline DOC URL & http:/hdl.handle.net/2115/66337 \\
\hline Rights & $\begin{array}{l}\text { This article has been published in a revised form in Journal of the Marine Biological A ssociation of the United } \\
\text { Kingdom http://dx.doi.org } / 10.1017 \text { S002531541500212X. This version is free to view and download for private } \\
\text { research and study only. Not for re- distribution, re sale or use in derivative works. } \odot \text { copy right holder. }\end{array}$ \\
\hline Type & article (author version) \\
\hline File Information & Noda et al. (JMBA 2015).pdf \\
\hline
\end{tabular}

Instructions for use 
Journal of the Marine Biological Association of the United Kingdom, page 1 of 7.

\# Marine Biological Association of the United Kingdom, 2015

doi:10.1017/S002531541500212X

ROCKY INTERTIDAL ZONATION AFTER MEGA-EARTHQUAKE

\title{
Recovery of rocky intertidal zonation: two years after the 2011 Great East Japan Earthquake
}

\author{
Takashi Noda $^{1}$, Aiko Iwasaki ${ }^{1,2}$, Keiichi Fukaya $^{3}$ \\ ${ }^{1}$ Faculty of Environmental Earth Science, Hokkaido University, Sapporo, Hokkaido, Japan \\ ${ }^{2}$ Graduate School of Environmental Science, Hokkaido University, Sapporo, Hokkaido, Japan \\ ${ }^{3}$ The Institute of Statistical Mathematics, Tachikawa, Tokyo, Japan
}

*Corresponding author. E-mail: noda@ees.hokudai.ac.jp

To assess the course and status of recovery of rocky intertidal zonation after massive subsidence caused by the 2011 Great East Japan Earthquake, from 2011 to 2013 we censused the vertical distribution of 10 dominant macrobenthic species (6 sessile and 4 mobile species) in the mid-shore zone of 23 sites along the Sanriku coastline, 150-160 km north-northwest of the earthquake epicenter, and compared the vertical distributions of each species with their vertical distributions in the pre-earthquake period. The dynamics of rocky intertidal zonation varied substantially among species. Among sessile species, one barnacle dramatically increased in abundance and expanded its vertical range in 2011, but then decreased and completely disappeared from all plots by 2013. Zonations of other sessile species shifted downward following the subsidence in 2011. With some species, there was no clear change in abundance immediately after the earthquake, but they then began to increase and move upward after a few years; with other species, abundance continuously decreased. There was no clear change in the vertical distribution of any of the mobile species immediately after the earthquake. Abundance of two mobile species was unchanged, but abundance of the others decreased from 2012 and had not recovered as of 2013.

Keywords: benthos, distribution, disturbance, earthquake, rocky intertidal, seaweed, subsidence, tsunami, zonation, Pacific coast 


\section{INTRODUCTION}

In the Pacific "Ring of Fire," large earthquakes $\left(>M_{\mathrm{w}} 8.0\right)$ that trigger tsunamis and coseismic uplift or subsidence take place repeatedly with an interval of decades or centuries (Lay \& Kanamori, 2011; Tajima et al., 2013). The impacts of these earthquakes are vast in the context of spatial scale; tsunamis and land-level changes affect hundreds of kilometers of coastline (Lay \& Kanamori, 2011; Tajima et al., 2013) and have great potential to affect coastal communities. This is because tsunami waves can transport benthos from their suitable habitats (Castilla, 1988; Castilla et al., 2010; Whanpetch et al., 2010; Lomovasky et al., 2011; Takami et al., 2013), heavily damage seagrass beds (Whanpetch et al., 2010) and coral reefs (Chavanich et al., 2005; Campbell et al., 2007), and remove and redeposit coastal sediments on a large spatial scale (Lomovasky et al., 2011). Subsidence, too, may have a substantial impact because it can transport substrate with attached organisms to deeper places.

On 11 March 2011, the powerful "2011 Great East Japan Earthquake" $\left(M_{\mathrm{w}} 9.0\right)$ struck off the Pacific coast of the Tohoku region of Japan. This mega-earthquake caused a large tsunami (run-up height exceeding $30 \mathrm{~m}$ ) and subsidence of $35-70 \mathrm{~cm}$ over the entire Tohoku region (Lay \& Kanamori, 2011; Tajima et al., 2013). As with all coastal communities, rocky intertidal communities may have suffered heavy damage. This is because organisms in this habitat may be damaged not only by the tsunami but also by subsidence. Distributions of most rocky intertidal species are restricted to within a narrow vertical range of several tens of centimeters (Stephenson \& Stephenson, 1972), suggesting that rocky intertidal organisms, especially sessile species, will be greatly affected by land-level changes over only a small vertical range. Indeed, previous studies have demonstrated that uplifts cause mass mortality of various sessile species and consequently alter rocky intertidal communities on a regional scale (Haven, 1972; Johansen, 1972; Bodin \& Klinger, 1986; Castilla, 1988; Castilla et al., 2010). The impact of subsidence, however, on these communities has not been reported previously, except for qualitative evaluations of changes in position of zonation of sessile organisms (Haven, 1972; Johansen, 1972).

On rocky shores, intertidal zonation is a striking and general pattern of organismal distribution (Stephenson \& Stephenson, 1972). The zonation would have been altered by the 2011 Great East Japan Earthquake. First, the number and distribution of each rocky intertidal species would very likely have been changed immediately due to the direct effects of subsidence and the tsunami, and then have been further altered by changes in population processes such as mortality and recruitment. In addition, the direct impact of the earthquake on the population and subsequent changes in distribution and abundance is expected to differ among species. To confirm these predictions, long-term population data obtained from several sites before the event are essential (Parker \& Wiens, 2005). For 8 years before the 2011 Great East Japan Earthquake we had regularly carried out community censuses targeting all macrobenthic species at 23 sites on five shores close to the epicenter of the earthquake (Okuda et al., 2004; Nakaoka et al., 2006; Fukaya et al., 2010; Munroe $\&$ Noda, 2010).

Most previous studies that have estimated the impacts of earthquakes on coastal populations have been conducted at relatively small spatial scales, that is, at only a single site or only a few sites (Whanpetch et al., 2010; Lomovasky et al., 2011). Because the influence of local coastal topography on the wave impact of a tsunami can be strengthened by stochastic effects (Wijetunge, 2006; Mori et al., 2011), in cases when only one or a few sites are selected for sampling, the stochastic effects can become too large to obtain a general picture of regional-scale impacts of the tsunami. Our objective, on the other hand, is to form a general picture of the impact of the 2011 mega-earthquake and associated subsidence and subsequent changes in zonation of rocky intertidal organisms, an aspect that has not yet been reported. To achieve this, we conducted a before/after comparison of zonation of several mid-tidal species, obtained as the averaged vertical distribution profile from 23 plots from five shores. This method allowed us to create a general picture of the regional-scale impacts of the mega-earthquake and subsequent succession of rocky intertidal assemblages.

Here we report the course and status of recovery of the vertical distribution of 10 dominant rocky intertidal macrobenthic species (6 sessile and 4 mobile species) in the mid-shore zone of 23 
sites, located 150-160 km north-northwest of the epicenter of the 2011 Great East Japan Earthquake, within 3 years after the mega-earthquake, by comparing the vertical gradient of abundance of each species at 4,16 , and 28 months after the mega-earthquake with those obtained from the pre-earthquake period (2003-2010).

\section{MATERIALS AND METHODS}

\section{Census design}

The impact of the 2011 Great East Japan Earthquake and subsequent change in rocky intertidal zonations was monitored at 23 sites on five shores, 2.6 to $7.9 \mathrm{~km}$ apart, along the Pacific coast of Honshu Island, northern Japan (Figure 1). The study shores are located 150-160 km north-northwest of the epicenter $\left(38^{\circ} 06^{\prime} 12.0^{\prime \prime} \mathrm{N}, 142^{\circ} 51^{\prime} 36.0^{\prime \prime} \mathrm{E}\right)$ of the 2011 Great East Japan Earthquake. Detailed descriptions of the biogeographic features of the area can be found in Okuda et al. (2004), Nakaoka et al. (2006), and Fukaya et al. (2010).

Within each shore, four or five sites were haphazardly chosen from semi-exposed locations, which exposed to wind-generated waves from ca. $180^{\circ}$, while wind from the opposite direction generates minimal wave action, with distances between neighboring plots ranging from 7.8 to $209 \mathrm{~m}$ (mean \pm SD, $59.2 \pm 70.3 \mathrm{~m}$ ). In July 2002 at each site, a permanent plot was marked with plastic or stainless steel anchors drilled into roughly vertical rock delimiting a study area that was $50 \mathrm{~cm}$ horizontally by $100 \mathrm{~cm}$ vertically, centered at mid-tide. The vertical extent of each permanent plot $(100 \mathrm{~cm})$ covered $72.4 \%$ of the tidal range $(138.2 \mathrm{~cm}$ between the mean high water and the mean low water of spring tides). In March 2011, the census area experienced coseismic subsidence of around $50 \mathrm{~cm}$ due to the 2011 Great East Japan Earthquake. In July 2011, we therefore vertically extended the 50-cm-wide permanent plots by an additional $100 \mathrm{~cm}$, with the lower border of the new part of the plot sharing the top border of each original permanent plot, so that the vertical observation range was now $200 \mathrm{~cm}$.

Permanent plots were monitored at low tide in July from 2003 to 2010 and from 2011 to 2013. In all censuses, abundances of each mobile species were estimated in quadrats $50 \mathrm{~cm}$ wide by $10 \mathrm{~cm}$ high (10 quadrats before the earthquake; 20 quadrats after the earthquake), which represented vertical sections of each permanent plot. In addition, coverage of each sessile species was estimated by a point sampling method that counted the number of times the focal species appeared on one of the 20 points of a $5-\mathrm{cm}$ by $5-\mathrm{cm}$ grid in each quadrat.

To estimate the vertical subsidence at each shore, we measured the vertical deviations (i.e., differences in height) between sea surface level and the height of anchors drilled at the mid-point of each original plot on all shores. We took these measurements during low tide on three calm days (in July 2011, May 2012, and July 2012), and assumed a measurement precision of $5 \mathrm{~cm}$. (We believe that our estimation of elevation of sea surface is accurate to within $5 \mathrm{~cm}$ because ocean waves cause fluctuations in sea surface level and actual tidal levels are expected to have deviations of a few centimeters from the predicted tidal levels published in tide tables.) Note that the resolution of the subsidence measurements $(5-\mathrm{cm} \mathrm{scale})$ corresponds to the resolution of measurements of vertical profiles of abundance of organisms. Vertical subsidence at each plot was estimated by using the vertical deviations and the predicted tide levels at the time of measurement estimated from tide tables published by the Japan Meteorological Agency, and we took the average of the three vertical ranges of subsidence in each plot to be the estimated subsidence range. Vertical subsidence was estimated to be $50 \mathrm{~cm}$ at four shores (Myojin, Oura, Aragami, and Katagishi) and $60 \mathrm{~cm}$ at Akahama.

\section{Before/after earthquake comparison of zonations}

By using data accumulated from all permanent plots, we obtained vertical distribution as mean abundance at the elevation position of each of the quadrats relative to mean tidal level. To secure reliable estimations of population sizes of each species, we excluded from further analyses rare 
species for which mean values of the total abundance in each year in the permanent plots before the earthquake were less than 25 for sessile species and less than 100 for mobile species.

We evaluated the influence of the earthquake on the change in vertical zonation of each species by before/after comparison in quadrats located at the same height relative to mean tidal level. Unfortunately, this method involves introducing a potential bias into the estimation of the impact of the earthquake depending on the original vertical distribution of each species. For example, for a species whose distribution is not changed after the earthquake, if this species had its pre-earthquake mode of distribution below the range of the plot, then its abundance appears to tend to increase after the earthquake. Therefore, the best approach for assessing a detrimental impact on intertidal populations involves comparing population surveys covering the entire range of the vertical distribution made before and after a perturbation. However, this was infeasible in this study, because the vertical distributions of most species in the plots were truncated in that they were observed in the top or the bottom quadrats representing the 10 sections of each plot. To diminish such problems, we selected species having a single mode in their vertical distribution, represented as the sum of the abundance in each of the 10 quadrats in the permanent plots before the earthquake.

To evaluate the course and status of recovery of vertical distribution of rocky intertidal macrobenthos within 3 years after the mega-earthquake, we constructed graphs depicting the abundance-elevation relationship of each species. In these graphs the $\mathrm{x}$-axis represents the elevational position of the quadrat expressed as the devation relative to the mean tidal level of the corresponding plot, and the $y$-axis represents coverage or abundance at each tidal level, which were calculated using data accumulated from all plots at each census. In these graphs, the coverage and abundance before the earthquake at each tidal level is shown as mean \pm 1.96 standard deviations of the data obtained from each census of the pre-earthquake period (2003-2010). Then we compared the vertical gradient of abundance of each species at 4,16 , and 28 months after the mega-earthquake with those obtained from the pre-earthquake period (2003-2010). This means that our inferences are based on the $95 \%$ prediction interval, which is an estimated interval within which future observations will fall with $95 \%$ probability, given what has been observed during the period before the earthquake. Thus, if the vertical profile of abundance falls outside the $95 \%$ prediction interval, it is a sign of a statistically significant difference in zonation before/after the earthquake.

\section{RESULTS}

\section{Sessile animals}

One barnacle, Semibalanus cariosus Pallas, 1788, dramatically increased in abundance and expanded its vertical range downward in 2011, but then decreased and completely disappeared from all plots in 2013 (Figure 2). Another barnacle, Chthamalus challengeri Hoek, 1883, shifted its zonation downward according to the subsidence in 2011, then expanded its zonation it upward in 2012, then shifted it upward again and consequently recovered its pre-earthquake zonation position in 2013 (Figure 2). The oyster Crassostrea gigas Thunberg, 1793, shifted its zonation downward according to the subsidence in 2011, then recovered to its normal vertical position in 2012, then increased its abundance in 2013 (Figure 2). Abundance of mussels including Septifer vergatus Wiegmann, 1837, and Mytilus spp. decreased continuously until 2013; they did not recover their vertical zonation position by the end of the survey period (Figure 2).

\section{Seaweeds}

The perennial brown alga Analipus japonicus Wynne, 1971, shifted its zonation downward according to the subsidence in 2011, then increased in abundance and moved further upward than it was before the earthquake in 2012. In 2013 it decreased somewhat but was still more abundant than before the earthquake (Figure 2). Abundance of the perennial crustose red alga Hildenbrandia rubra Meneghini, 1841, decreased continuously until 2013; it had still not recovered its vertical zonation position by 2013 (Figure 2). 


\section{Mobile animals}

None of the mobile species showed any clear change in their vertical distribution immediately after the earthquake (Figure 2). Among them, the limpets Lottia kogamogai Sasaki \& Okutani, 1994, and Lottia tenuisculpta Sasaki \& Okutani, 1994, had not altered their zonation in any of the censuses up to 2013. On the other hand, abundances of the limpet Notoacmea fuscoviridis Teramachi, 1949, and the herbivorous trochid Monodonta labio Linnaeus, 1758, decreased from 2011 to 2012 and had not recovered by 2013.

\section{DISCUSSION}

For 8 of the 10 species analyzed in the present study, their vertical distributions after the earthquake were considerably different from those before the earthquake. It is highly plausible that the abundance and vertical distribution of these species across the entire range of the study area were significantly altered by the 2011 Great East Japan Earthquake, accompanying large tsunami, and coseismic subsidence, as has been similarly reported in other studies showing that large earthquakes that triggered tsunamis and coseismic uplift heavily damaged rocky intertidal communities (Haven, 1972; Bodin \& Klinger, 1986; Castilla, 1988; Castilla \& Oliva, 1990; Kendall et al., 2006; Patterson Edwards et al., 2006; Sanpanich et al., 2006; Castilla et al., 2010).

The 2011 Great East Japan Earthquake ( $M_{\mathrm{w}} 9.0$ ) caused a large tsunami and subsidence of 50$60 \mathrm{~cm}$ over the entire study area. The considerable changes in distribution and abundance of rocky intertidal organisms that followed may have been mainly caused by coseismic subsidence rather than by the tsunami. For sessile species, all shifted their zonations downward according to the subsidence in 2011; however, none of them except for mussels (i.e., S. vergatus and Mytilus spp.) showed a clear decrease in abundance immediately after the earthquake, suggesting that the tsunami had only a weak negative impact. For mobile organisms, the immediate negative impacts of both the tsunami and subsidence may be negligibly weak. This is because none of the mobile species clearly changed their vertical distribution immediately after the earthquake. It is plausible that the decline in abundance of some sessile organisms (i.e., mussels and H. rubra) that continued until 2013 is caused by a delayed effect of subsidence rather than by the tsunami. This is because transport of such sessile species to deeper places should increase mortality by predation and/or competition, which determine the lower zonation limit of many sessile organisms (Connell, 1961, 1972; Paine, 1974; Underwood $\&$ Denley, 1984). In addition, the increase in abundance of several sessile organisms a few years after the earthquake may be related to subsidence but not the tsunami. For example, the barnacle $C$. challengeri shifted its zonation downward according to the subsidence immediately after the earthquake but expanded its vertical zonation upward the following year. The only organisms to be significantly damaged by the tsunami may be mussels, which are known to be susceptible to dislodgment by waves during storms (Dayton, 1971; Paine \& Levin, 1981; Sousa, 1984). Indeed, many new disturbance patches were found in the mussel beds in the permanent plots in July 2011 (Takashi Noda, personal observation).

The present study showed that changes in zonation after coseismic subsidence were clearly different from changes in zonation after coseismic uplift, in which mass mortality of zonation-forming species was observed within the year after the event, followed by downward shifts of zonation (Castilla, 1988; Castilla \& Oliva, 1990; Castilla et al., 2010). First, abundance of several sessile organisms increased after the earthquake. Second, the immediate impact of subsidence and subsequent population change varied considerably among species. Such differences in the outcomes of coseismic vertical displacement in opposite directions can be explained by the mechanisms underlying the results of transplant experiments in which sessile organisms are moved to locations beyond the upper and lower limits of their zonation. While individuals transported beyond their upper limit often died rapidly, probably due to desiccation or heat stress (Underwood \& Denley, 1984; Helmuth et al., 2006), individuals transported beyond their lower limit gradually decreased by 
predation or competition (Connell, 1961, 1972; Paine, 1974; Underwood \& Denley, 1984) but often grew more vigorously (Schonbeck \& Norton, 1980; Hawkins \& Hartnoll, 1985; Raffaelli \& Hawkins, 1996).

The results of the present study indicated that rocky intertidal communities at 3 years after the mega-earthquake have not yet returned to their normal state. For most species, zonation in 2013 was obviously different from zonation before the earthquake, and only three out of ten species have been consistently recovering to their pre-earthquake zonation. Furthermore, two species have been continuously decreasing since the earthquake, including mussels, which often play an important role in community organization in rocky intertidal communities by providing secondary substrata for interstitial organisms (Suchanek, 1986; Lohse, 1993; Miyamoto \& Noda, 2004) or by competitively displacing other species (Paine, 1966; Dayton, 1971; Menge, 1976; Miyamoto \& Noda, 2004).

Rocky intertidal communities will experience a long delay before fully recovering from the impact of the mega-earthquake. Species that have not recovered include late-successional sessile species, which grow slowly and have weak colonization ability, such as mussels (Paine \& Levin, 1981; Wootton, 1993) and perennial crustose red alga H. rubra (Wennberg, 1992). In addition, restoration of such damaged populations may not be well secured by any external supply of larvae or propagules from neighboring populations, because the coseismic subsidence occurred on such a large spatial scale encompassing entire metapopulations of those species (Kinlan \& Gaines, 2003). Furthermore, even though the distribution and abundance of some species might recover, this recovery might once again be directed away from the normal population status owing to the indirect influence of the earthquake via other species whose abundance and distribution remains abnormal. In this context, the course to recovery of the rocky intertidal communities is expected to be highly unpredictable. Indeed, our present study showed that there were substantial interspecific variations in temporal changes in distribution and abundance within the 3 years after the earthquake.

\section{CONCLUSION}

According to our results, the 2011 Great East Japan Earthquake significantly altered rocky intertidal zonation along the Sanriku coast 150-160 km north-northwest of the epicenter of the earthquake; this was mainly due to coseismic subsidence rather than the tsunami. Second, 3 years after the earthquake, rocky intertidal communities had not yet recovered to their normal pre-earthquake state. Unrecovered species include late-successional sessile species that grow slowly and have weak colonization ability; this suggests that rocky intertidal communities will experience a long delay in recovering from the impact of the earthquake. Third, the dynamics of rocky intertidal zonation following the earthquake and accompanying subsidence had two unique features: considerable interspecific variation and occasional increase in abundance of several organisms. Neither of these features has been reported for similar mega-earthquakes with accompanying uplift. In those cases, coseismic uplift resulted in mass mortality of zonation-forming species within 1 year after the event followed by downward shifts of zonation.

\section{ACKNOWLEDGMENTS}

We thank Dr. T. Okuda, Dr. M. Tsujino, T. Hagino, M. Iida, R. Sahara, M. Ohira, and Y. Kanamori for field assistance. For field and laboratory facilities, we are grateful to the staff and students of the International Coastal Research Center of the Atmosphere and Ocean Research Institute, The University of Tokyo. This study was made possible by the generous support and encouragement of the local fisherman and fishery offices of the Fisherman's Cooperative Associations in Iwate. 
This research was supported by the Cooperative Program of the Atmosphere and Ocean Research Institute, The University of Tokyo (Grant Nos. 108, 104, 107, 101, and 103 in 2006, 2007, 2008, 2009 , and 2010, respectively, to TN), and was partly supported by Japan Society for the Promotion of Science KAKENHI grants (Nos. 20570012, 24570012, and 15K07208 to TN) and the Tohoku Ecosystem-Associated Marine Sciences (TEAMS) project. The funders had no role in the study design, data collection and analysis, decision to publish, or preparation of the manuscript.

\section{REFERENCES}

Bodin P. and Klinger T. (1986) Coastal uplift and mortality of intertidal organisms caused by the September 1985 Mexico earthquakes. Science 233, 1071-1073.

Campbell S. J., Pratchett M. S., Anggoro A. W., Ardiwijaya R. L., Fadli N., Herdiana Y., Kartawijaya T., Mahyiddin D., Mukminin A., Pardede S. T., Rudi E., Siregar A. M. and Baird A. H. (2007) Disturbance to coral reefs in Aceh, Northern Sumatra: impacts of the Sumatra-Andaman tsunami and pre-tsunami degradation. Atoll Research Bulletin 544, 55-78.

Castilla J. C. (1988) Earthquake-caused coastal uplift and its effects on rocky intertidal kelp communities. Science 242, 440-443.

Castilla J. C. and Oliva D. (1990) Ecological consequences of coseismic uplift on the intertidal kelp belts of Lessonia nigrescens in central Chile. Estuarine Coastal and Shelf Science 31, 45-56.

Castilla J. C., Manríquez P. H. and Camaño A. (2010) Effects of rocky shore coseismic uplift and the 2010 Chilean mega-earthquake on intertidal biomarker species. Marine Ecology Progress Series 418, 17-23.

Chavanich S., Siripong A., Sojisuporn P. and Menasveta P. (2005) Impact of tsunami on the seafloor and corals in Thailand. Coral Reefs 24, 535-535.

Connell J. H. (1961) The influence of intra-specific competition and other factors on the distribution of the barnacle Chthamalus stellatus. Ecology 42, 710-723.

Connell J. H. (1972) Community interactions on marine rocky intertidal shores. Annual Review of Ecology Evolution and Systematics 3, 169-192.

Dayton P. K. (1971) Competition, disturbance, and community organization: the provision and subsequent utilization of space in a rocky intertidal community. Ecological Monographs 41, $351-389$.

Fukaya K., Okuda T., Nakaoka M., Hori M. and Noda T. (2010) Seasonality in the strength and spatial scale of processes determining intertidal barnacle population growth. Journal of Animal Ecology 79, 1270-1279.

Haven S. B. (1972) Effects of land level changes on intertidal invertebrates with discussion of postearthquake ecological succession. In Committee on the Alaska Earthquake of the Division of Earth Sciences National Research Council (ed), The Great Alaska Earthquake of 1964: biology. National academy of science, publication 1604, Washington, DC: National Academy of Science, pp. 82-106.

Hawkins S. J. and Hartnoll R. G. (1985) Factors determining the upper limits of intertidal canopy-forming algae. Marine Ecology Progress Series 20, 265-271.

Helmuth B., Mieszkowska N., Moore P. and Hawkins S. J. (2006) Living on the edge of two changing worlds: forecasting the responses to climate change of rocky intertidal ecosystems. Annual Review of Ecology Evolution and Systematics 37, 373-404. 
Johansen H. W. (1972) Effects of elevation changes on benthic algae in Prince William Sound. In Committee on the Alaska Earthquake of the Division of Earth Sciences National Research Council (ed), The Great Alaska Earthquake of 1964: biology. National academy of science, publication 1604, Washington, DC: National Academy of Science, pp. 35-68.

Kendall M. A., Paterson G. L. J., Aryuthaka C., Nimsantijaroena S., Kongkaeouw W. and Whanpetch N. (2006) Impact of the 2004 tsunami on intertidal sediment and rocky shore assemblages in Ranong and Phang Nga provinces, Thailand. Phuket Marine Biological Center Research Bulletin 67, 63-75.

Kinlan B. P. and Gaines S. D. (2003) Propagule dispersal in marine and terrestrial environments: a community perspective. Ecology 84, 2007-2020.

Lay T. and Kanamori H. (2011) Insights from the great 2011 Japan earthquake, Physics Today 64: 33-39.

Lohse D. P. (1993) The importance of secondary substratum in a rocky intertidal community. Journal of Experimental Marine Biology and Ecology 166, 1-17.

Lomovasky B. J., Firstater F. N., Salazar A. G., Mendo J. and Iribarne O. O. (2011) Macro benthic community assemblage before and after the 2007 tsunami and earthquake at Paracas Bay, Peru. Journal of Sea Research 65, 205-212.

Menge B. A. (1976) Organization of the New England rocky intertidal community: role of predation, competition, and environmental heterogeneity. Ecological Monographs 46, 355-393.

Miyamoto Y. and Noda T. (2004) Effects of mussels on competitively inferior species: competitive exclusion to facilitation. Marine Ecology Progress Series 276, 293-298.

Mori N., Takahashi T., Yasuda T. and Yanagisawa H. (2011) Survey of 2011 Tohoku earthquake tsunami inundation and run-up. Geophysical Research Letters 38 (L00G14): 6 pp, doi:10.1029/2011GL049210

Munroe D. M. and Noda T. (2010) Physical and biological factors contributing to changes in the relative importance of recruitment to population dynamics in open populations. Marine Ecology Progress Series 412, 151-162.

Nakaoka M., Ito N., Yamamoto T., Okuda T. and Noda T. (2006) Similarity of rocky intertidal assemblages along the Pacific coast of Japan: effects of spatial scales and geographic distance. Ecological Research 21: 425-435.

Okuda T., Noda T., Yamamoto T., Ito N. and Nakaoka M. (2004) Latitudinal gradient of species diversity: multi-scale variability in rocky intertidal sessile assemblages along the Northwestern Pacific coast. Population Ecology 46, 159-170.

Paine R. T. (1966) Food web complexity and species diversity. American Naturalist 100, 65-75.

Paine R. T. (1974) Intertidal community structure: experimental studies on the relationship between a dominant competitor and its principal predator. Oecologia 15, 93-120.

Paine R. T. and Levin S. A. (1981) Intertidal landscapes: disturbance and the dynamics of pattern. Ecological Monographs 51, 145-178.

Parker K. R. and Wiens J. A. (2005) Assessing recovery following environmental accidents: environmental variation, ecological assumptions, and strategies. Ecological Applications 15, 2037-2051.

Patterson Edwards J. K., Kulkanri S., Jeyabaskaran R., Lazarus S., Mary A., Venkataraman K., Das S. P., Tamelander J., Rajasuriya A., Jayakumar K., Kumaraguru A. K., Marimuthu N., Sluka R. and Jerald Wilson J. (2006) The effects of the 2004 tsunami on mainland India and the Andaman and Nicobar Islands. In Wilkinson C., Souter D. and Goldberg J. (eds), Status of coral reefs in tsunami affected countries: 2005. Townsville: Australian Institute for Marine Studies, pp. 85-97.

Raffaelli D. and Hawkins S. (1996) Intertidal ecology. London: Chapman \& Hall.

Sanpanich K., Wells F. E. and Chitramvong Y. (2006) Effects of the 26 December 2004 tsunami on littorinid molluscs near Phuket, Thailand. Journal of Molluscan Studies 72, 311-313.

Schonbeck M. W. and Norton T. A. (1980) Factors controlling the lower limits of fucoid algae on the shore. Journal of Experimental Marine Biology and Ecology 43, 131-151.

Sousa W. P. (1984) Intertidal mosaics: patch size, propagule availability, and spatially variable patterns of succession. Ecology 65, 1918-1935. 
Stephenson T. A. and Stephenson A. (1972) Life between tidemarks on rocky shores. San Francisco: Freeman.

Suchanek T. H. (1986) Mussels and their role in structuring rocky shore communities. In Moore P. G. and Seed R. (eds), The ecology of rocky coasts., New York: Columbia University Press, pp.70-96.

Tajima F., Mori J. and Kennett B. L. N. (2013) A review of the 2011 Tohoku-Oki earthquake (Mw 9.0): Large-scale rupture across heterogeneous plate coupling. Tectonophysics 586, 15-34.

Takami H., Won N-I. and Kawamura T. (2013) Impacts of the 2011 mega-earthquake and tsunami on abalone Haliotis discus hannai and sea urchin Strongylocentrotus nudus populations at Oshika Peninsula, Miyagi, Japan. Fisheries Oceanography 22, 113-120.

Underwood A. J. and Denley E. J. (1984) Paradigms, explanations and generalizations in models for the structure of intertidal communities on rocky shores. In Strong D. R. Jr, Simberloff D., Abele L. G. and Thistle A. B. (eds) Ecological communities: conceptual issues and the evidence. Princeton: Princeton University Press, pp. 151-180.

Wennberg T. (1992) Colonization and succession of macroalgae on a breakwater in Laholm Bay, a eutrophicated brackish water area (SW Sweden). Acta Phytogeographica Suecica 78, 65-77.

Whanpetch N., Nakaoka M., Mukai H., Suzuki T., Nojima S., Kawai T. and Aryuthaka C. (2010) Temporal changes in benthic communities of seagrass beds impacted by a tsunami in the Andaman Sea, Thailand. Estuarine, Coastal and Shelf Science 87, 246-252.

Wijetunge J. J. (2006) Tsunami on 26 December 2004: spatial distribution of tsunami height and the extent of inundation in Sri Lanka. Science of Tsunami Hazards 24, 225-239.

Wootton J. T. (1993) Size-dependent competition: effects on the dynamics vs. the endpoint of mussel bed succession. Ecology 74, 195-206. 


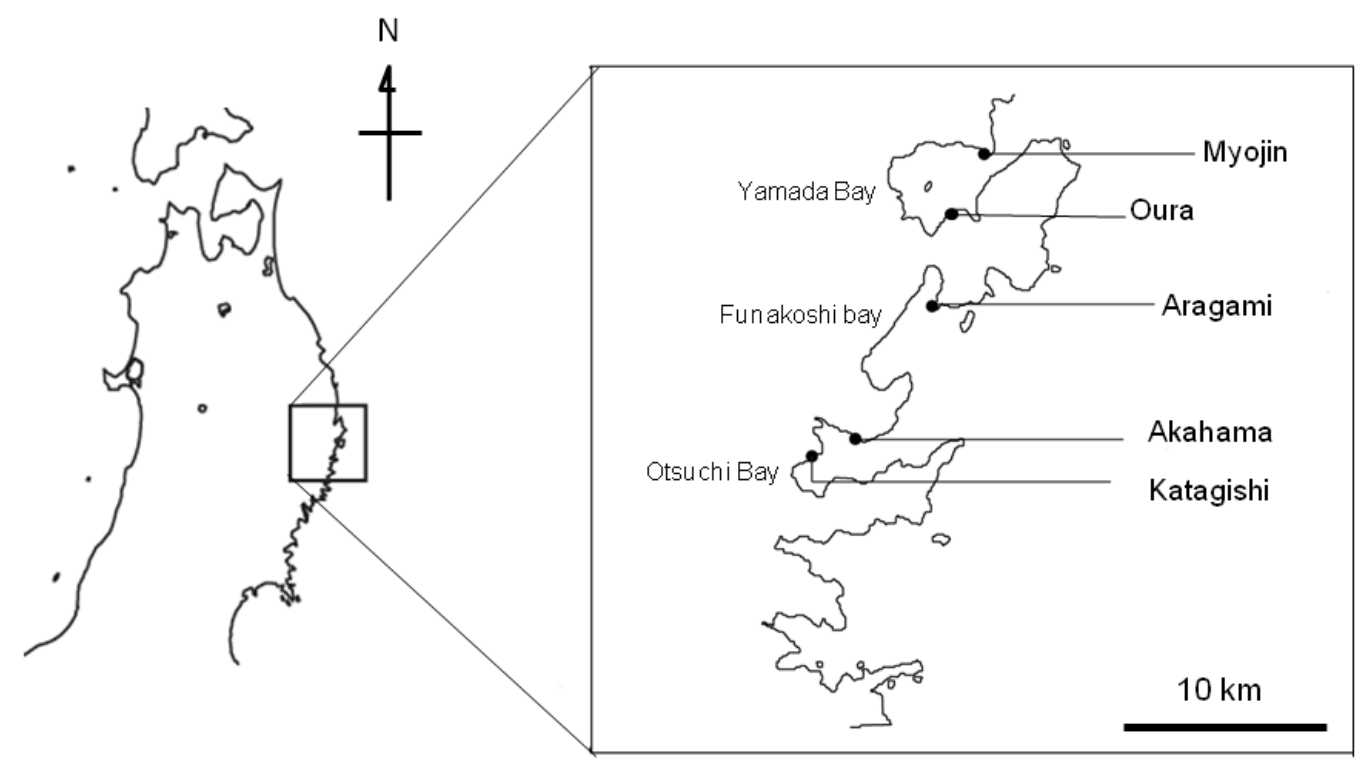

Fig 1.

Fig. 1. Map of study sites. Five rocky shores were chosen for the census of intertidal organisms on the Sanriku coast along the Pacific coast of Japan. 


\section{Sessile animals}
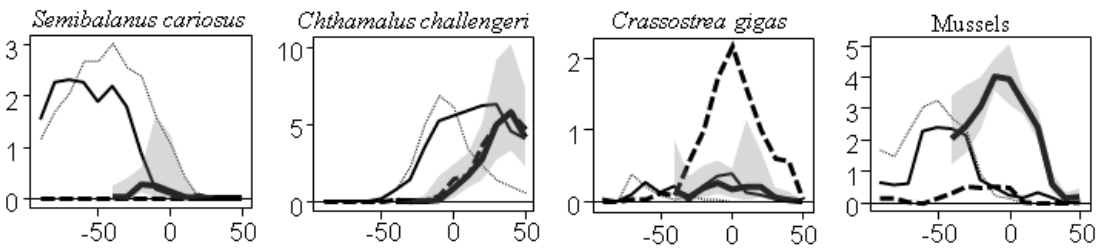

Sea weeds
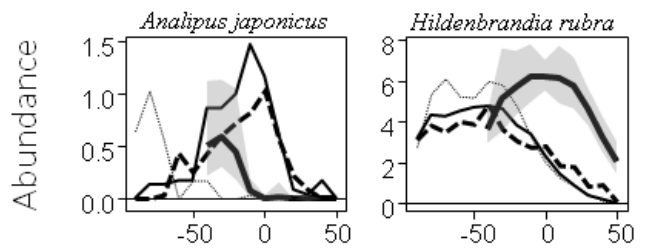

$$
\begin{aligned}
& \text { - Before the earthquake } \\
& \text { - } 2011 \text { July } \\
& \text {-- } 2012 \text { July } \\
& \text { 2013 July }
\end{aligned}
$$

Mobile animals
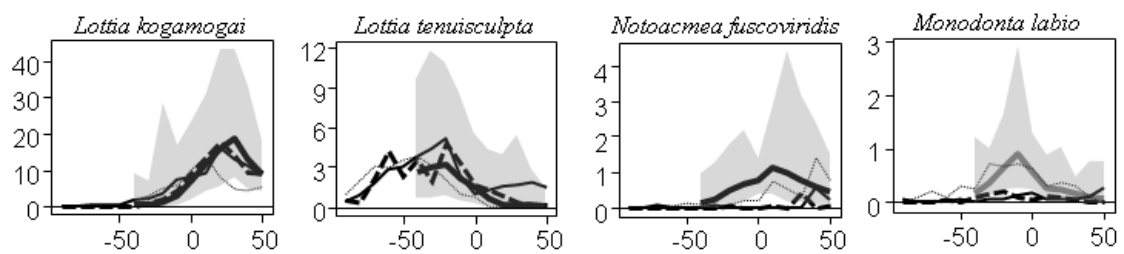

Distance from mean tidal level $(\mathrm{cm})$

Fig. 2. Course and status of recovery of vertical distribution of rocky intertidal macrobenthos within 3 years after the mega-earthquake along the coast at locations $150-160 \mathrm{~km}$ north-northwest of the epicenter of the 2011 Great East Japan Earthquake. Tidal level on the $x$-axis represents elevation position of the quadrat relative to the mean tidal level of each corresponding plot (see the subsection Census Design in the Materials and Methods section for details). Coverage and abundance at each tidal level were calculated using data accumulated from all plots at each census. Coverage and abundance before the earthquake at each tidal level is shown as mean \pm 1.96 standard deviations of data obtained from each census of the pre-earthquake period (2003-2010). 